\title{
Reservoir operation using grey fuzzy stochastic dynamic programming
}

\author{
Fi-John Chang,* Shyh-Chi Hui and Yen-Chang Chen \\ Department of Bioenvironmental Systems Engineering, National Taiwan University, Taipei, Taiwan, R.O.C
}

\begin{abstract}
:
This paper presents an optimal regulation programme, grey fuzzy stochastic dynamic programming (GFSDP), for reservoir operation. It is composed of a grey system, fuzzy theory and dynamic programming. The grey system represents data by covering the whole range without loss of generality, and the fuzzy arithmetic takes charge of the rules of reservoir operation. The GFSDP deals with the multipurpose decision-making problem by fuzzy optimization theorem. The practicability and effectiveness of the proposed approach is tested on the operation of the Shiman reservoir in Taiwan. The current M5 operating rule curves of this reservoir also are evaluated. The simulation results demonstrate that this new approach, in comparison with the M5 rule curves, has superior performance with regard to the total water deficit and number of monthly deficits. Copyright (C) 2002 John Wiley \& Sons, Ltd.
\end{abstract}

KEY WORDS fuzzy arithmetic; grey system; reservoir operation; stochastic dynamic programming

\section{INTRODUCTION}

Taiwan's annual average rainfall is about $2600 \mathrm{~mm}$. Compared with other countries, Taiwan should have plentiful water, but owing to the characteristics of Taiwan's watersheds (erodible soil, uneven rainfall, steep slopes and high mountains), most of the water runs directly into the sea; only 20 per cent water can be stored for use. Water resources are becoming important issues in Taiwan because of the continuous increase in water demand accompanying economic growth, opposition to the construction of new reservoirs by the heightened desire for environmental protection, and dwindling number of suitable dam sites. At the same time, the serious reduction in storage capacity of existing reservoirs caused by sedimentation makes water resources management even more complicated. Unless reservoir operation can be improved drastically, water shortages will occur more frequently. It is thus natural that reservoir operation has emerged as an urgent and difficult task to be studied for the sustainable utilization of water resources in Taiwan.

In general, the vast majority of studies of reservoir operation technique rely on simulation and optimization approaches. Because of the rapid progress in computers, the optimization approach can now be carried out easily. Dynamic programming (DP) was developed originally by Bellman (1957). Dynamic programming consists of an objective function, which is assumed to be a set of decisions, and of the constraints, which represent the financial, physical and institutional limitations of the system. The objective function may be either maximized or minimized to meet the goal. In Taiwan's reservoir operation, the objective function usually is the optimal amount of release from a reservoir. Dynamic programming offers a relatively flexible means of modelling and has been applied to solving problems of reservoir operation (Hall and Buras, 1961). However, the computation of DP was time consuming. Many methods were proposed to improve DP for reservoir operation. Bras et al. (1983) used non-stationary control stochastic dynamic programming (SDP) to present a real-time stream-flow forecast in reservoir operation. Datta and Houck (1984) combined DP and

* Correspondence to: F.-J. Chang, Department of Bioenvironmental Systems Engineering, National Taiwan University, Taipei, Taiwan, R.O.C. E-mail: changfj@ccms.ntu.edu.tw. 
forecast error to form chance-constrained SDP for real-time forecasts. Stedinger et al. (1984) used SDP to calculate the expected benefits for future reservoir operation. Trezos and Yeh (1987) developed differential SDP for large-scale reservoir operation systems. Kelman et al. (1990) presented sampling stochastic dynamic programming (SSDP) by using a large number of sample stream-flow sequences to improve the reservoir operating policy. Karamouz and Vasiliadis (1992) developed Bayesian stochastic dynamic programming (BSDP), which continuously updated the probabilities with new incoming information to generate optimal operating rules. Archibald et al. (1996) developed an aggregate stochastic dynamic programming model to determine the policy of multireservoir operating systems.

The present study develops a grey fuzzy stochastic dynamic programming (GFSDP) model that consists of fuzzy arithmetic and a grey system for determining reservoir operating strategies. The method proposed is different from the mathematical programming pursuing the deterministic solution. It is not meaningful to have an optimal solution because of the ambiguities and uncertainties in objectives and constraints. The GFSDP model deals with the representative intervals of inflow and outflow using grey arithmetic and handles the multipurpose decision-making problem by fuzzy arithmetic. Grey arithmetic can be used to deal with uncertainties and to address the imprecision of the input and output, and the fuzzy arithmetic provides a suitable way to deal with ambiguity and uncertainty. Instead of black and white logic for grey relationships, the GFSDP holds that the information for reservoir operation is a matter of degree. All the possible hydrological and operating conditions also are considered when the model is established. Thus, GFSDP can behave as an adaptive system and create a set of more flexible optimal reservoir operating rules. In the following sections, the theories and formulae of the model are described first. It is then implemented for the Shiman Reservoir, Taiwan.

\section{GREY SYSTEM}

The grey system was introduced originally by Deng (1984). In this system, the information falls into three categories: white with completely certain information, grey with insufficient information, and black with totally unknown information. The grey system deals with the information (data) belonging to the grey category. Owing to insufficient information, most of the statistical characteristics of the system cannot be identified. However, the data available reveal the range of information. A grey number for the system can be expressed mathematically as

$$
\begin{aligned}
a^{ \pm} & =\left[a^{+}, a^{-}\right] \\
& =\left\{t \in a^{ \pm} \mid a^{-} \leq t \leq a^{+}\right\}
\end{aligned}
$$

where $a^{ \pm}$is a grey number; $t$ is information; $a^{+}$and $a^{-}$are the upper and lower limits of the information. Thus, the uncertainty in the parameters can be expressed by the grey number. The flexible solutions of the system can be obtained by transforming uncertainty by the grey number through stochastic dynamic programming processes. The operation of the grey number is defined as follows

$$
a^{ \pm} \otimes b^{ \pm}=\left[\min \left(a^{-}, b^{-}\right), \max \left(a^{+}, b^{+}\right)\right]
$$

where $\otimes$ is an operator. The operation of the grey function can be defined as

$$
\left[f\left(a_{1}^{ \pm}, a_{2}^{ \pm}, \ldots, a_{n}^{ \pm}\right)\right]^{ \pm}=\left\{\left[f\left(a_{1}^{ \pm}, a_{2}^{ \pm}, \ldots, a_{n}^{ \pm}\right)\right]^{-},\left[f\left(a_{1}^{ \pm}, a_{2}^{ \pm}, \ldots, a_{n}^{ \pm}\right)\right]^{+}\right\}
$$

where $\left[f\left(a_{1}^{ \pm}, a_{2}^{ \pm}, \ldots, a_{n}^{ \pm}\right)\right]^{ \pm}$is the value of the grey function; $\left[f\left(a_{1}^{ \pm}, a_{2}^{ \pm}, \ldots, a_{n}^{ \pm}\right)\right]^{-}$and $\left[f\left(a_{1}^{ \pm}, a_{2}^{ \pm}, \ldots, a_{n}^{ \pm}\right)\right]^{+}$ are the minimum and maximum values of the function. Equation (3) shows that $f\left(a_{1}^{ \pm}, a_{2}^{ \pm}, \ldots, a_{n}^{ \pm}\right)$is not a grey number, but $a_{1}^{ \pm}, a_{2}^{ \pm}, \ldots, a_{n}^{ \pm}$are grey numbers. 


\section{FUZZY ARITHMETIC}

The notion of fuzzy sets was first proposed by Zadeh (1965) to represent vagueness in linguistics in a mathematical way. Fuzzy arithmetic provides a good approach to dealing with ambiguity and uncertainty. It combines rule base and fuzzy control to describe non-linear characteristics in nature. The rule base is the collection of rules. A rule contains two statements, the premise and the conclusion. It is a logical implication: IF premise THEN conclusion. For example, classic logic theory can represent only one colour in black and white. This logic does not accord well in grey. Fuzzy logic, which can be used to represent vague concepts, lets elements be represented by degrees of membership. The degree of membership is a positive real number in the interval $[0,1]$. A membership function assigns a degree of membership to an element and can be any shape. Using the centroid defuzzification method, the fuzzy control output can be determined as follows

$$
\begin{gathered}
\text { IF } a \text { is } M^{i} \text { THEN } y^{I} \\
\hat{Y}=\frac{\sum_{i=1}^{n} M^{i}(a) y^{i}}{\sum_{i=1}^{n} M^{i}(a)}
\end{gathered}
$$

in which $\hat{Y}$ is the fuzzy control output, $M^{i}(a)$ is the degree of membership of the $i$ th rule, $a$ is the input, $y^{i}$ is the output of the $i$ th rule and $n$ is the number of the rule.

\section{GREY FUZZY STOCHASTIC DYNAMIC PROGRAMMING}

The forward-moving solution procedure is used for grey fuzzy stochastic dynamic programming. Figure 1 illustrates sequential reservoir operation processes. In each stage $t$, the inflow and release of the reservoir are $I_{t}$ and $R_{t}$. The goal of the reservoir operation is to create the maximum benefit, $\sum f_{t}$. The capacity of the reservoir at stage $t, S_{t}$, is the capacity at the end of stage $t-1$. Thus, the state transformation equation of non-invertible form for stage $t$ is defined as

$$
S_{t}=S_{t-1}+I_{t-1}-R_{t-1}-E_{t-1} A\left(S_{t-1}, S_{t}\right)
$$

where $E_{t-1}$ is the rate of evaporation and $A\left(S_{t-1}, S_{t}\right)$ is the water surface of the reservoir.

A stochastic dynamic programming with grey variables is called grey stochastic dynamic programming (GSDP). The recursive equation of GSDP that includes $h$ objectives can be written

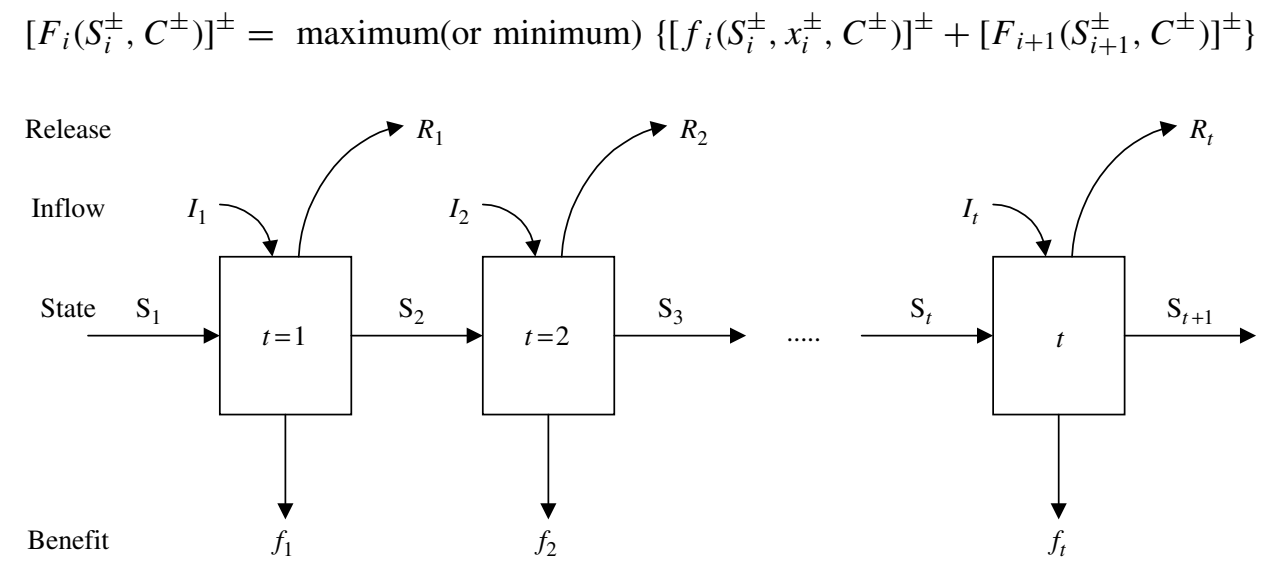

Figure 1. Sequential reservoir operation processes 
in which $f_{i}(\bullet)$ is the objective function at stage $i, x_{i}$ is a decision variables $C$ is a constant, such as temperature or water surface of reservoir, that can be input with an intervals $S_{i+1}^{ \pm}$is grey state variable at $t+1$ stage, and can be defined as

$$
S_{i+1}^{ \pm}=\left[T_{i}\left(S_{i}^{ \pm}, x_{i}^{ \pm}, C^{ \pm}\right)\right]
$$

where $T_{i}(\bullet)$ is a state transformation function that represents the storage of the reservoir at the end of stage $i$. Equation (7) can be split into the following two equations

$$
\begin{aligned}
& {\left[F_{i}\left(S_{i}, I_{i-1}\right)\right]^{+}=\max \left(\text { or min) }\left\{\sum_{k=1}^{z}\left[p\left[I_{i, k} \mid I_{i-1}\right]\left[\left[f_{i}\left(S_{i}^{ \pm}, R_{i}^{ \pm}, I_{i, k}^{ \pm}\right)\right]^{+}+F_{i+1}\left[S_{i+1}^{ \pm}, I_{i, k}^{ \pm}\right]^{+}\right]\right]\right\}\right.} \\
& {\left[F_{i}\left(S_{i}, I_{i-1}\right)\right]^{-}=\max \text { (or min) }\left\{\sum_{k=1}^{z}\left[p\left[I_{i, k} \mid I_{i-1}\right]\left[\left[f_{i}\left(S_{i}^{ \pm}, R_{i}^{ \pm}, I_{i, k}^{ \pm}\right)\right]^{-}+F_{i+1}\left[S_{i+1}^{ \pm}, I_{i, k}^{ \pm}\right]^{-}\right]\right]\right\}}
\end{aligned}
$$

where $p\left[I_{i, k} \mid I_{i-1}\right]$ is the probability of $I_{i, k}$ if $I_{i-1}$ also occurs, $p\left(I_{i, k}\right)$ is the probability of inflow in the $i$ th stage given inflow condition $k$ and $z$ is the number of inflow conditions. In this study, $z=3$ (high, normal and low water levels). The state transformation function of Equations (9) and (10) is

$$
R_{i, k}^{ \pm}=S_{i}^{ \pm}-S_{i+1}^{ \pm}+I_{i, k}^{ \pm}
$$

where the evaporation loss, $E_{t}$, is ignored to simplify the model. Equations (9) and (10) are the optimal solutions subjected to the best and worst conditions. The recursive relationship equation of the $p$ th objective is as follows

$$
{ }_{p} F_{i}\left(S_{i}, I_{i-1}\right)=\max (\text { or min })\left\{\sum_{k=1}^{z}\left[p\left[I_{i, k} \mid I_{i-1}\right]\left[{ }_{p} f_{i}\left(S_{i}, R_{i}, I_{i, k}\right)+{ }_{p} F_{i+1}^{*}\left(S_{i+1}, I_{i, k}\right)\right]\right]\right\}
$$

where ${ }_{p} F_{i+1}^{*}\left(S_{i+1}, I_{i, k}\right)$ is the optimal solution of objective $p$ with $S_{i+1}$ at stage $i+1$ and $p=1,2, \ldots, h$.

For every objective of reservoir operation, each stage could have $n$ possible states. Then $n$ decisions for each stage would be created and represented by Chen's fuzzy theory (Chen and Jiang, 1990). The $p$ th objective with $n$ possible decisions that can be used for determining water release becomes

\begin{tabular}{|c|c|c|c|c|}
\hline & Decision 1 & Decision 2 & Decision $m$ & Decision $n$ \\
\hline $\begin{array}{l}\text { Objective } 1 \\
\text { Objective } 2\end{array}$ & $\begin{array}{l}{ }_{1} F_{i}^{1}\left(S_{i}, I_{i-1}\right) \\
{ }_{2} F_{i}^{1}\left(S_{i}, I_{i-1}\right)\end{array}$ & $\begin{array}{l}{ }_{1} F_{i}^{2}\left(S_{i}, I_{i-1}\right) \\
{ }_{2} F_{i}^{2}\left(S_{i}, I_{i-1}\right)\end{array}$ & $\begin{array}{l}{ }_{1} F_{i}^{m}\left(S_{i}, I_{i-1}\right) \\
{ }_{2} F_{i}^{m}\left(S_{i}, I_{i-1}\right)\end{array}$ & $\begin{array}{l}{ }_{1} F_{i}^{n}\left(S_{i}, I_{i-1}\right) \\
{ }_{2} F_{i}^{n}\left(S_{i}, I_{i-1}\right)\end{array}$ \\
\hline Objective $p$ & ${ }_{p} F_{i}^{1}\left(S_{i}, I_{i-1}\right)$ & ${ }_{p} F_{i}^{2}\left(S_{i}, I_{i-1}\right)$ & ${ }_{p} F_{i}^{m}\left(S_{i}, I_{i-1}\right)$ & ${ }_{p} F_{i}^{n}\left(S_{i}, I_{i-1}\right)$ \\
\hline Objective $h$ & ${ }_{h} F_{i}^{1}\left(S_{i}, I_{i-1}\right)$ & ${ }_{h} F_{i}^{2}\left(S_{i}, I_{i-1}\right)$ & ${ }_{h} F_{i}^{m}\left(S_{i}, I_{i-1}\right)$ & ${ }_{h} F_{i}^{n}\left(S_{i}, I_{i-1}\right)$ \\
\hline
\end{tabular}

$$
{ }_{p} F_{i}^{1}\left(S_{i}, I_{i-1}, S_{i+1}^{1}\right),{ }_{p} F_{i}^{2}\left(S_{i}, I_{i-1}, S_{i+1}^{2}\right), \ldots,{ }_{p} F_{i}^{m}\left(S_{i}, I_{i-1}, S_{i+1}^{m}\right), \ldots,{ }_{p} F_{i}^{n}\left(S_{i}, I_{i-1}, S_{i+1}^{n}\right)
$$

where ${ }_{p} F_{i}^{m}\left(S_{i}, I_{i-1}, S_{i+1}^{m}\right)={ }_{p} F_{i}^{m}\left(S_{i}, I_{i-1}\right)$ is the net benefit during period $i$ when the decision $m$ is made. Thus all the objectives of the model that can be the possible water release in stage $i$ will be 
The weight of the $m$ th decision of the $p$ th objective in stage $i$ can be calculated as

$$
\begin{aligned}
{ }_{p} r_{i}^{m} & =\frac{{ }_{p} F_{i}^{m}\left(S_{i}, I_{i-1}\right)}{\max _{m=1}^{n} F_{i}^{m}\left(S_{i}, I_{i-1}\right)} \\
{ }_{p} r_{i}^{m} & =1-\frac{{ }_{p} F_{i}^{m}\left(S_{i}, I_{i-1}\right)}{\max _{m=1}^{n} F_{i}^{m}\left(S_{i}, I_{i-1}\right)}
\end{aligned}
$$

Equation (14) should be used when the objective is to find the maximum benefit, such as hydropower generation. For finding the minimum benefit, i.e. the water deficit, Equation (15) is used in this model. Then, the best and worst solutions during period $i$ and starting in state $S_{i}$ are defined by

$$
\begin{aligned}
G_{i} & =\left(\bigcup_{m=1}^{n}{ }_{1} r_{i}^{m}, \bigcup_{m=1}^{n}{ }_{2} r_{i}^{m}, \ldots, \bigcup_{m=1}^{n}{ }_{h} r_{i}^{m}\right) \\
& =\left(g_{1},{ }_{2} g_{i}, \ldots,{ }_{h} g_{i}\right) \\
B_{i} & =\left(\bigcap_{m=1}^{n} r_{i} r_{i}^{m}, \bigcap_{m=1}^{n}{ }_{2} r_{i}^{m}, \ldots, \bigcap_{m=1}^{n}{ }_{h} r_{i}^{m}\right) \\
& =\left({ }_{1} b_{i},{ }_{2} b_{i}, \ldots,{ }_{h} b_{i}\right)
\end{aligned}
$$

where $\cup$ and $\cap$, which are the union and intersection operators, are the max and min, respectively. Thus the fuzzification matrix with decision $m$ during period $i$ at state $S_{i}$ represents the Chen's degree of membership of reservoir operation based on the best and worst solutions that can be derived

$$
U_{i}=\left[\begin{array}{llll}
u_{1,1} & u_{1,2} & \ldots u_{1, m} \ldots & u_{1, n} \\
u_{2,1} & u_{2,2} & \ldots u_{2, m} \ldots & u_{2, n}
\end{array}\right]
$$

$U_{i}$ is all of the Chen's degree of membership based on the best and worst solutions during the $i$ th stage. $u_{1, m}$ is the Chen's degree of membership of the $m$ th decision based on the best solution that is derived by calculating the fuzzification matrix by minimizing the distances between ${ }_{p} r_{i}^{m}$ and $G_{i}$ and ${ }_{p} r_{i}^{m}$ and $B_{i}$. The distance needed to be determined can be calculated by differentiating the equation, and is given by

$$
\min \left\{H=\sum_{m=1}^{n}\left[\left(u_{1, m} d\left({ }_{p} r_{h}^{m}, G_{i}\right)\right)^{2}+\left(u_{2, m} d\left({ }_{p} r_{h}^{m}, B_{i}\right)\right)^{2}\right]\right\}
$$

Equation (19) can be written

$$
\min \left\{H=\sum_{m=1}^{n}\left[u_{i, m}^{2}\left(\sum_{p=1}^{h}\left(W_{p}\left({ }_{p} r_{i}^{m}-{ }_{p} g_{i}\right)\right)^{2}\right)+\left(1-u_{1, m}\right)^{2}\left(\sum_{p=1}^{h}\left(W_{p}\left({ }_{p} r_{i}^{m}-{ }_{p} b_{i}\right)\right)^{2}\right)\right]\right\}
$$

where $W_{p}$ is the weight for objective $p ; \sum_{p=1}^{h}\left(W_{p}\left({ }_{p} r_{i}^{m}-{ }_{p} g_{i}\right)\right)^{2}$ and $\sum_{p=1}^{h}\left(W_{p}\left({ }_{p} r_{i}^{m}-{ }_{p} b_{i}\right)\right)^{2}$ are the sum of squares of the distances between the $m$ th decision and the best and the worst solutions. They should always be positive. Solving Equation (20) yields

$$
u_{1, m}=\frac{1}{1+\frac{\sum_{p=1}^{h}\left(W_{p}\left({ }_{p} r_{i}^{m}-{ }_{p} g_{i}\right)\right)^{2}}{\sum_{p=1}^{h}\left(W_{p}\left({ }_{p} r_{i}^{m}-{ }_{p} b_{i}\right)\right)^{2}}}=\frac{1}{1+\left[\frac{d\left({ }_{p} r_{i}^{m}, G_{i}\right)}{d\left({ }_{p} r_{i}^{m}, B_{i}\right)}\right]^{2}}
$$


where $d\left({ }_{p} r_{i}^{m}, G_{i}\right)$ denotes the distance between ${ }_{p} r_{i}^{m}$ and $G_{i}$. The details of the solution from Equation (20) are given in the Appendix. The Chen's degree of membership of the $m$ th decision during period $i$ at state $S_{i}$ based on the worst solution, $u_{2, m}$, can be calculated by replacing $u_{i, m}$ by $1-u_{i, m}$.

After the optimal solutions of every stage based on $z$ different inflows are obtained, fuzzy arithmetic is used to determine the release of the reservoir. Figure 2 describes the optimal solutions at different stages with $k=3$ (low, normal and high inflows). Parameters $G_{1}, G_{2}$ and $G_{3}$ are the initial gauge height at stage $i+1$ depending on the inflows of stage $i-1$ and the initial gauge height at stage $i$. Figure 3 shows the Gaussian membership functions for reservoir operation with three different inflows. The Gaussian function is given as

$$
M_{k}=\exp \left[-\frac{\left(Q_{k}-\mu_{k}\right)^{2}}{\sigma_{k}^{2}}\right]
$$

where $\sigma_{k}$ is the widths $\mu_{k}$ is the centres $Q_{k}$ is the inflow and $1 \leq k \leq z$. The degree of membership is determined by the inflow of the last month. Thus, the release of reservoir at stage $i$ is determined by

$$
G_{r}=\frac{\sum_{k=1}^{z} M_{k} G_{k}}{\sum_{k=1}^{z} M_{k}}
$$

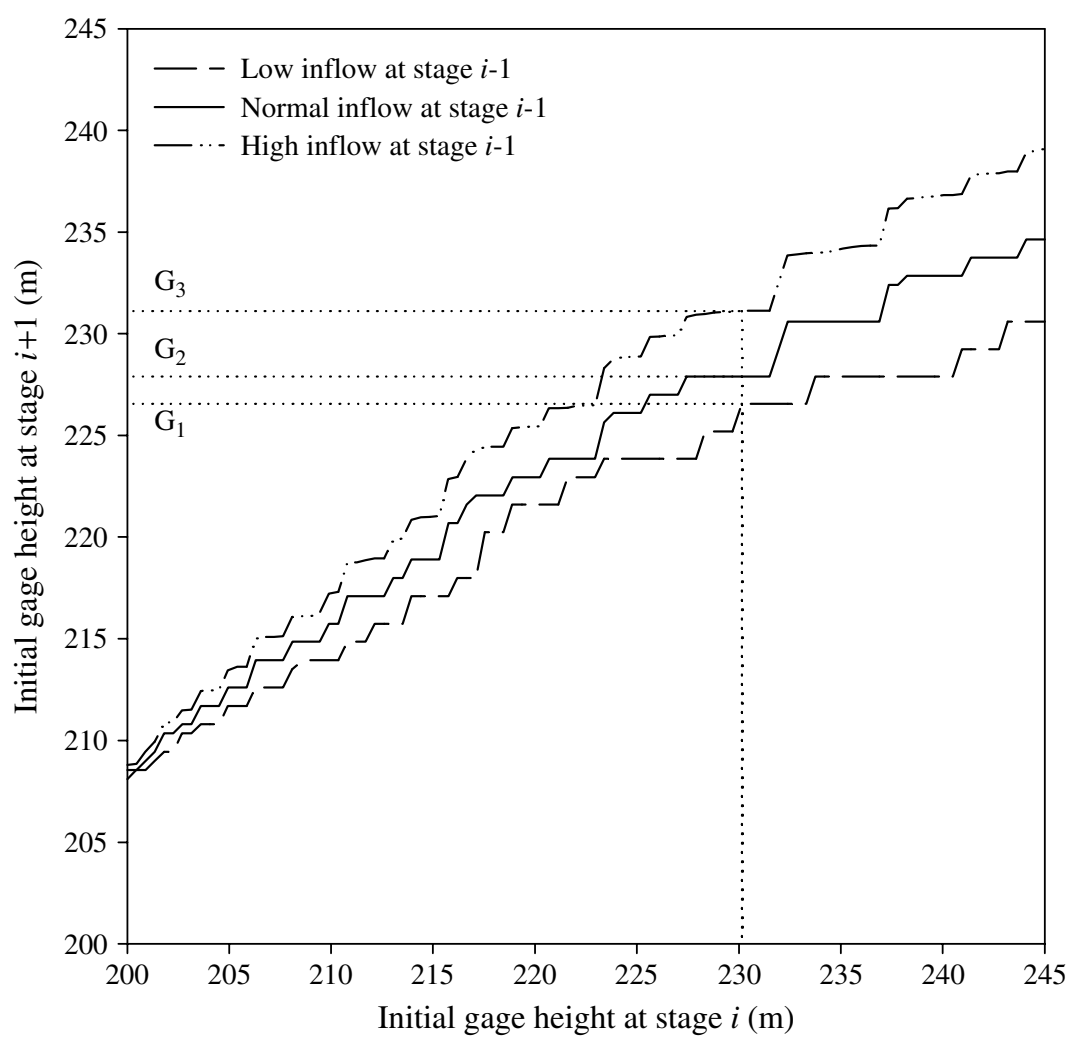

Figure 2. The optimal release at stage $i+1$ 


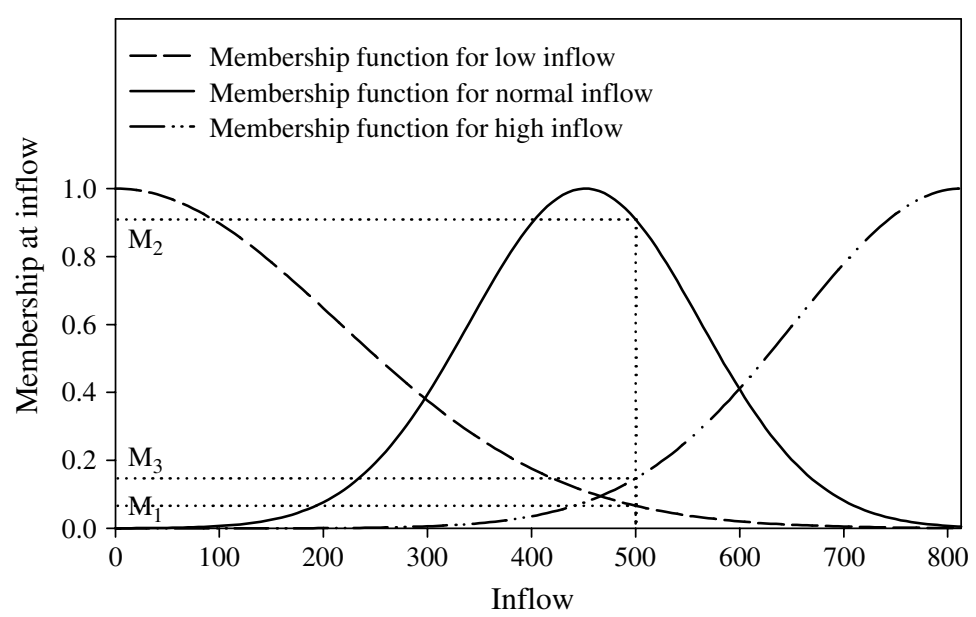

Figure 3. Membership at inflow

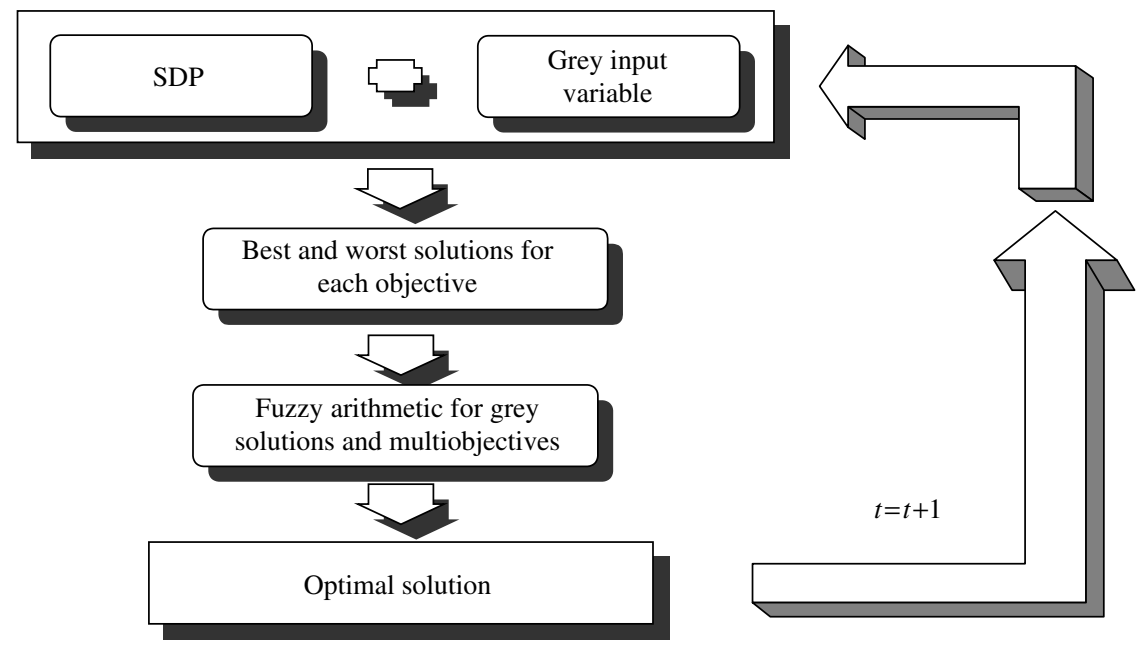

Figure 4. Structure of grey fuzzy stochastic dynamic programming

where $M_{k}$ is the degree of membership with different inflows. Figure 4 shows the structure of GFSDP. It represents that the best and worst solutions of each objective are obtained through SDP and grey input variables. The fuzzy arithmetic is then used to deal with the grey solutions within each objective, and find the optimal solution of multi-objectives.

\section{CASE STUDY}

The Tanshui River, the third largest river in Taiwan, is situated near the metropolis of Taipei (Figure 5). The catchment area, which extends from high mountains (elevation $3530 \mathrm{~m}$ ) to sea level, drains an area of $2762 \mathrm{~km}^{2}$ to the Taiwan Strait. As present water demands are continuously expanding, and probably will continue to do so, two reservoirs, Feitsui and Shiman, have been constructed. The Shiman Reservoir is located on the Tahan Creek, which is the upstream of the Tanshui River. Within the Tahan Creek catchment area the river is $135 \mathrm{~km}$ long and the average slope is $2.7 \%$. The catchment receives an average (1964-1988) 


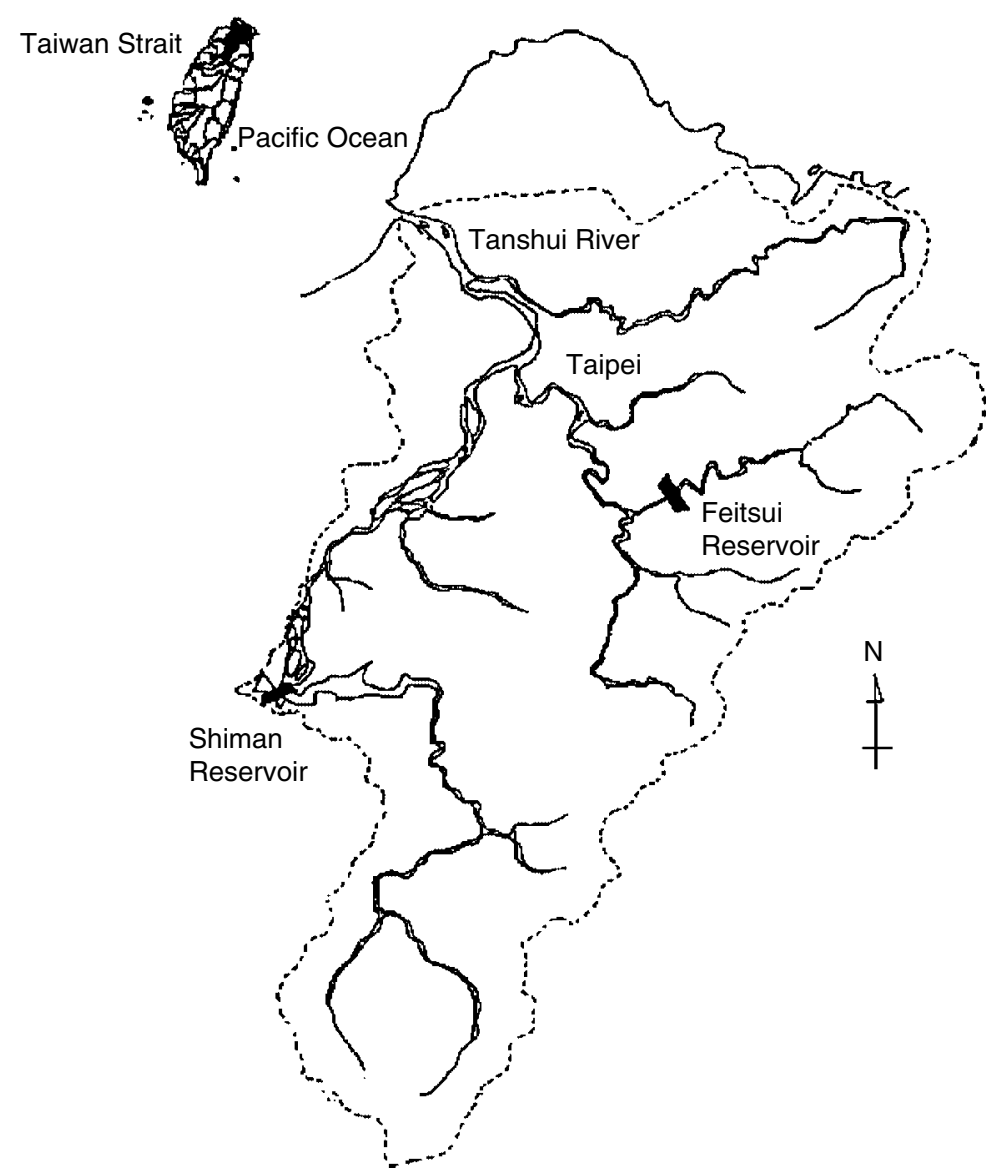

Figure 5. Locations of the Tanshui River basin and the Shiman Reservoir

of $2409 \mathrm{~mm}$ of rainfall; however, the rainfall is uneven-over $70 \%$ occurs between May and October. The Shiman Reservoir was built not only for municipal and industrial water supply but also for irrigation, flood control and power generation. The operation plan of the Shiman reservoir is based on the M5 rule curve, as shown in Figure 6. The lowest, lower and upper curves are used for irrigation, power generation and food control, respectively. A careful evaluation of water use shows that the water needed to the year 2010 appears to increase drastically. Therefore, the authority of the Shiman Reservoir will need to develop an efficient operation policy for the challenge of future water demands.

The monthly inflow, release, gauge height and storage of the Shiman Reservoir measured from 1964 to 1993 are used for verifying the grey fuzzy stochastic dynamic programming. Table I summarizes the water demands in every month for the year of 2001. Table II describes the mean, standard deviation, and historical maximum and minimum of the monthly inflows of the Shiman Reservoir. Table III shows the parameters used for determining the membership functions. The boundaries of low, normal and high inflows are defined by containing the 20th percentile of the smaller historical data set, the middle $80 \%$ data, and the 20th percentile of the larger data set, respectively. Parameters $\mu_{1}$ and $\mu_{3}$ are set to be the lower and upper limits of their data, and $\mu_{2}$ is the centre of the normal inflow data. Parameters $\sigma_{1}$ and $\sigma_{3}$ are set to be the $90 \%$ interval of the data, and $\sigma_{2}$ is $45 \%$.

Two objectives, i.e. storage and release, are concerned in this case study. The objective of storage is relative to flood control, hydropower generation and recreation purposes, whereas the objective of release deals mainly 


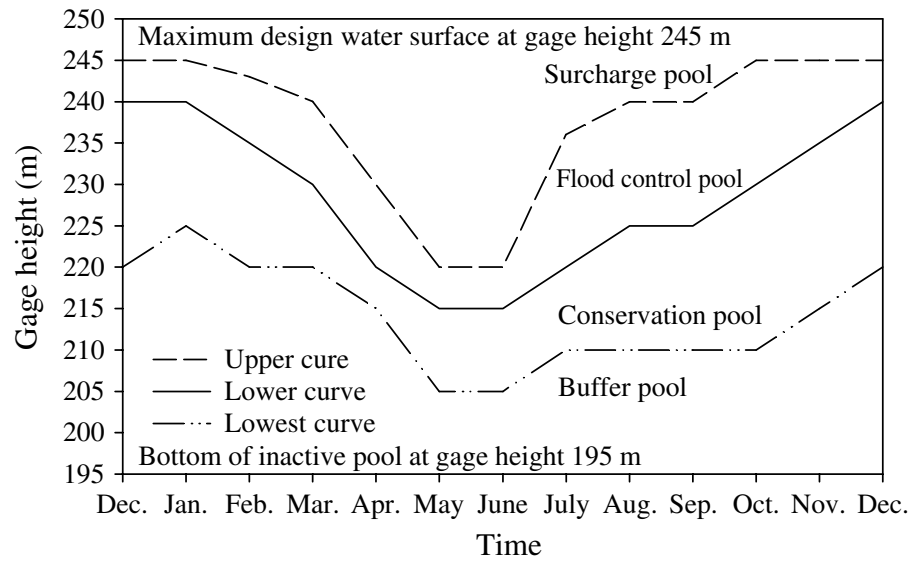

Figure 6. Rule curve for the Shiman Reservoir

Table I. Water demands in every month for the year 2001

\begin{tabular}{lccc}
\hline Month & $\begin{array}{c}\text { Municipal and } \\
\text { industrial supply } \\
\left(\text { million } \mathrm{m}^{3}\right)\end{array}$ & $\begin{array}{c}\text { Irrigation } \\
\left(\text { million } \mathrm{m}^{3}\right)\end{array}$ & $\begin{array}{c}\text { Total } \\
\left(\text { million } \mathrm{m}^{3}\right)\end{array}$ \\
\hline January & 484 & 206 & 690 \\
February & 453 & 515 & 968 \\
March & 518 & 738 & 1256 \\
April & 525 & 603 & 1128 \\
May & 580 & 568 & 1148 \\
June & 597 & 548 & 1145 \\
July & 644 & 752 & 1396 \\
August & 689 & 696 & 1385 \\
September & 606 & 576 & 1182 \\
October & 592 & 580 & 1172 \\
November & 519 & 303 & 822 \\
December & 508 & 32 & 540 \\
\hline
\end{tabular}

with water supply for both public and agricultural users. The inflow, release and goal of storage are designed as grey variables. The objectives and constraints are shown as the follows

1. Objective equations

$$
\min \left[{ }_{1} F_{i}\left(S_{i}, I_{i-1}\right)\right]^{+}, \quad \min \left[{ }_{1} F_{i}\left(S_{i}, I_{i-1}\right)\right]^{-}
$$

and

$$
\min \left[{ }_{2} F_{i}\left(S_{i}, I_{i-1}\right)\right]^{+}, \quad \min \left[2 F_{i}\left(S_{i}, I_{i-1}\right)\right]^{-}
$$

2. Recursive equations of the storage objective

$$
\begin{aligned}
& {\left[{ }_{1} F_{i}\left(S_{i}, I_{i-1}\right)\right]^{+}=\min \left\{\sum_{k=1}^{3}\left[p\left(I_{i, k} \mid I_{i-1}\right)\left(\left[{ }_{1} f_{i}\right]^{+}+\left[{ }_{1} F_{i+1}^{*}\left(S_{i+1}, I_{1, k}\right)\right]^{+}\right)\right]\right\}} \\
& {\left[{ }_{1} F_{i}\left(S_{i}, I_{i-1}\right)\right]^{-}=\min \left\{\sum_{k=1}^{3}\left[p\left(I_{i, k} \mid I_{i-1}\right)\left(\left[{ }_{1} f_{i}\right]^{-}+\left[{ }_{1} F_{i+1}^{*}\left(S_{i+1}, I_{1, k}\right)\right]^{-}\right)\right]\right\}}
\end{aligned}
$$


Table II. Statistics of inflow data

\begin{tabular}{|c|c|c|c|c|}
\hline Month & $\begin{array}{l}\text { Maximum } \\
\text { monthly inflow } \\
\left(\text { million } \mathrm{m}^{3}\right)\end{array}$ & $\begin{array}{l}\text { Minimum } \\
\text { monthly inflow } \\
\left(\text { million } \mathrm{m}^{3}\right)\end{array}$ & $\begin{array}{c}\text { Mean } \\
\left(\text { million } \mathrm{m}^{3}\right)\end{array}$ & $\begin{array}{c}\text { Standard } \\
\text { deviation } \\
\left(\text { million } \mathrm{m}^{3}\right)\end{array}$ \\
\hline January & 964 & 223 & 446 & 179 \\
\hline February & 3343 & 204 & 701 & 804 \\
\hline March & 4732 & 254 & 946 & 891 \\
\hline April & 3165 & 163 & 852 & 609 \\
\hline May & 2049 & 318 & 1015 & 441 \\
\hline June & 5316 & 793 & 1985 & 1110 \\
\hline July & 3808 & 433 & 1441 & 1001 \\
\hline August & 9067 & 360 & 2681 & 2269 \\
\hline September & 8535 & 396 & 2934 & 2292 \\
\hline October & 6719 & 401 & 1810 & 1392 \\
\hline November & 2355 & 313 & 739 & 426 \\
\hline December & 823 & 247 & 449 & 143 \\
\hline
\end{tabular}

and

$$
\left[{ }_{1} f_{i}\right]^{ \pm}=\min \left\{\left(S_{i}-X_{i}^{ \pm}\right)^{2}\right\}
$$

3. Recursive equations of the release objective:

$$
\begin{aligned}
& {\left[{ }_{2} F_{i}\left(S_{i}, I_{i-1}\right)\right]^{+}=\min \left\{\sum_{k=1}^{3}\left[p\left(I_{i, k} \mid I_{i-1}\right)\left(\left[{ }_{2} f_{i}\right]^{+}+\left[{ }_{2} F_{i+1}^{*}\left(S_{i+1}, I_{1, k}\right)\right]^{+}\right)\right]\right\}} \\
& {\left[{ }_{2} F_{i}\left(S_{i}, I_{i-1}\right)\right]^{-}=\min \left\{\sum_{k=1}^{3}\left[p\left(I_{i, k} \mid I_{i-1}\right)\left(\left[{ }_{2} f_{i}\right]^{-}+\left[{ }_{2} F_{i+1}^{*}\left(S_{i+1}, I_{1, k}\right)\right]^{-}\right)\right]\right\}}
\end{aligned}
$$

and

$$
\left[2 f_{i}\right]^{ \pm}=\min \left\{\left(r_{i, k}-D_{i}\right)^{2}\right\}^{ \pm}
$$

4. The state transformation equations

$$
r_{i, k}^{+}=S_{i}-S_{i+1}+I_{i, k}^{+}
$$

and

$$
r_{i, k}^{-}=S_{i}-S_{i+1}+I_{i, k}^{-}
$$

5. Constraints

$$
\begin{aligned}
& \text { Dead storage } \leq S_{i} \leq X_{i}^{+} \\
& S_{i}+I_{i, k}^{+}-X_{i}^{+}<r_{i, k}^{+}<S_{i}+I_{i, k}^{+}-\text {dead storage }
\end{aligned}
$$

and

$$
S_{i}+I_{i, k}^{-}-X_{i}^{-}<r_{i, k}^{-}<S_{i}+I_{i, k}^{-}-\text {dead storage }
$$

where $X_{i}^{+}$and $X_{i}^{-}$are the storage of the upper and lower curves in rule curve M5 at stage $i$, respectively; $D_{i}$ is the water demand at stage $i, i=1,2, \ldots, T ; T$ is the total number of the operating stage, which is equal to 12 in the case study. The definition of other variables can be found in previous sections. 


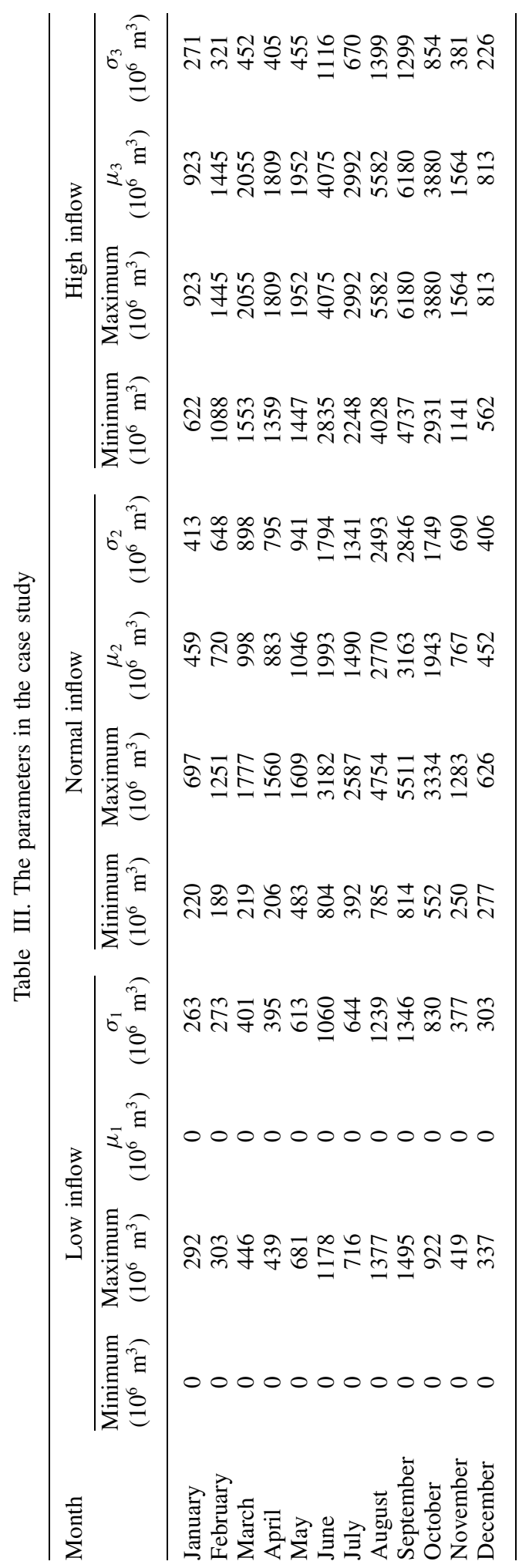


The performances of the proposed algorithm and M5 rule curve for the operation of the Shiman Reservoir are evaluated using the generalized shortage index (GSI) (Hsu, 1995), given by

$$
G S I=\frac{100}{N} \sum_{i=1}^{N}\left(\frac{D P Y_{i}}{100 \times D Y_{i}}\right)^{2}
$$

where $N$ is number of sample years, $D Y_{i}$ is number of the $i$ th year (365 or 366) and $D P Y_{i}$ is the deficit per cent year index of the $i$ th year, given by

$$
D P Y=\sum_{j=1}^{12}(M D R \times N M C)
$$

where $M D R$ is the monthly deficit rate (\%) and NMC is number of months in a continuous deficit. The GSI is an indicator of the social tolerance limits to water shortage that measures the monthly deficit rate. Under this criterion the model that produces the minimum GSI is the one with a better performance.

Figure 7 compares the monthly deficit resulting from the operation under the M5 rule curve with GFSDP. It shows that most of the points fall below the agreement line and the points that fall on the $y$-axis are less than those on the $x$-axis. The monthly deficit of GFSDP usually is observed to be smaller than the M5 rule curve. By using GFSDP the number of monthly deficits is reduced from 127 to 90 . The GSI obtained by GFSDP is 0.0001 , which is much smaller than 0.278 obtained by the M5 rule curve. It also indicates that GFSDP appears to provide better results. Figure 8 illustrates the yearly deficit obtained by both GFSDP and rule curve M5 and the difference between the two methods. The yearly deficit amount obtained by using GFSDP is much less than by rule curve M5 in most of the 29 years. There are only 4 years where the yearly deficit obtained by using the rule curve M5 is slightly less than by GFSDP. During the study period, the total deficit will be reduced significantly from 54.48 billion $\mathrm{m}^{3}$ to 32.42 billion $\mathrm{m}^{3}$ if GFSD is used. Both Figures 7 and 8 and GSI indicate that the performance of GFSDP is much better than the actual operation in reducing the total deficit volume, and the number of monthly and yearly deficit volumes.

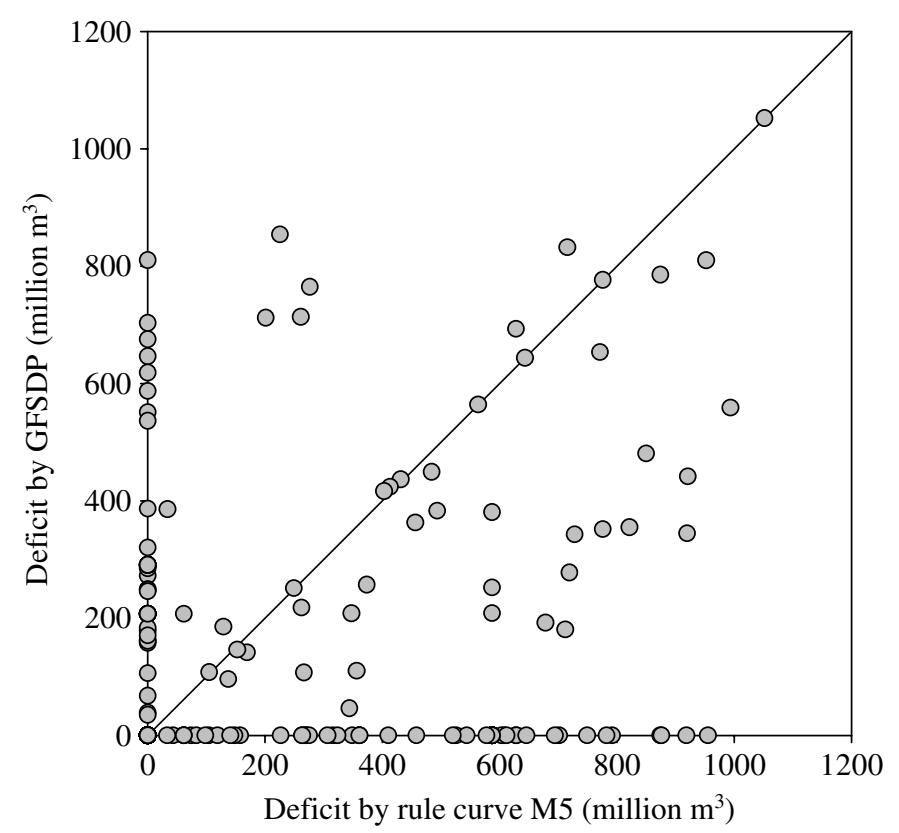

Figure 7. Comparison of deficit from grey fuzzy stochastic dynamic programming and rule curve M5 


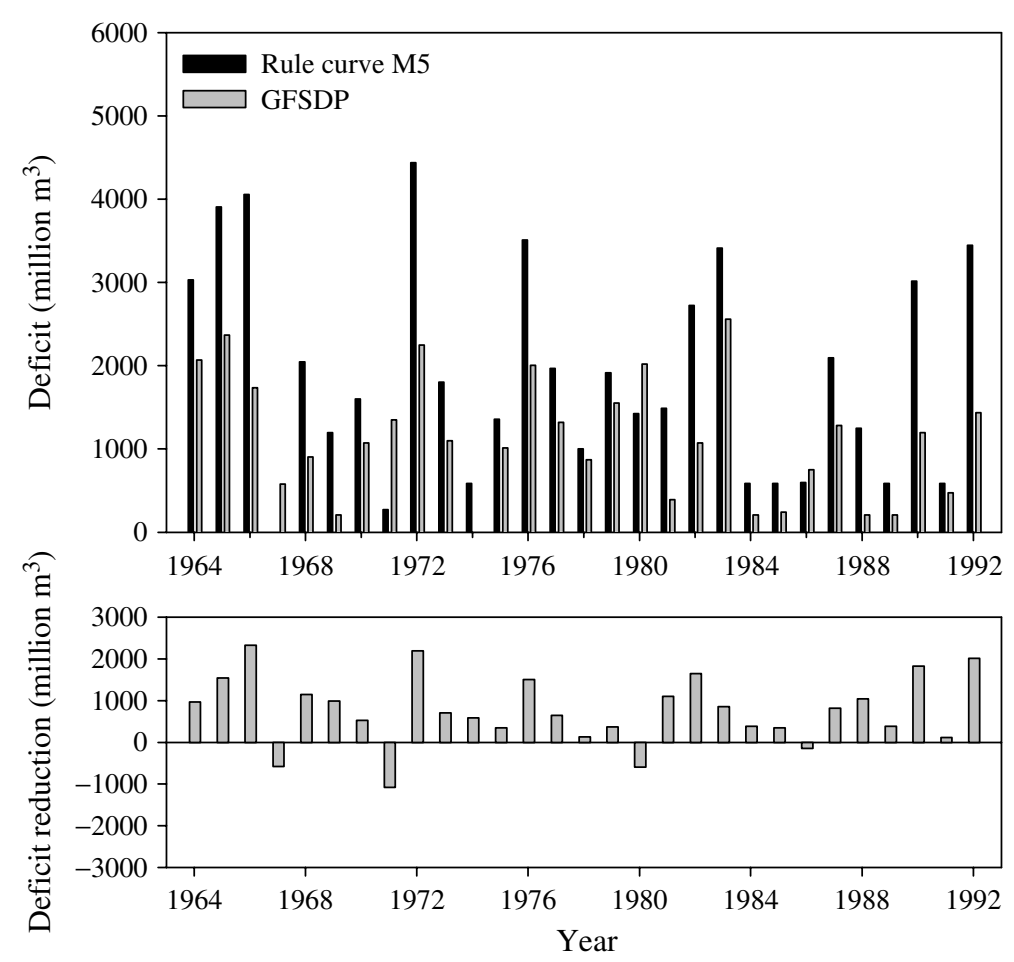

Figure 8. Comparison of model results and deficit reduction

\section{CONCLUSIONS}

A real-world reservoir operation can be very complex. It has to meet various demands without violating the constraints of the system. In addition, the uncertainties and ambiguities always arise from the system. Fortunately, uncertainty and ambiguity can be dealt with more efficaciously using grey and fuzzy arithmetics. In Taiwan, water shortage is a major socio-economic problem. The grey and fuzzy arithmetics are combined with the optimization approach to develop GFSDP for the improvement of reservoir operation. The grey stochastic dynamic program presents an interval of the solution, and the fuzzy arithmetic carries out the solution through the membership function. They can successfully communicate the uncertainty and ambiguity of the complex natural system to the optimization process. Making a careful choice of $\sigma$ and $\mu$ for input variables (inflow) is important, because they are sensitive to the model. The states of release for each stage can be divided according to the objectives and as estimated by Chen's fuzzy theory. The parameters can be estimated easily. However, the model will be influenced by the number and boundary of states. To verify the proposed model, GFSDP is used to simulate the operation of the Shiman Reservoir. The results show that GFSDP is an efficient and flexible tool for reservoir operation. It can significantly improve on the water release and reduce the water deficit values compared with the existing M5 rule curve.

\section{ACKNOWLEDGEMENTS}

This paper is based on partial work supported by National Science Council, Taiwan (Grant number NSC 89-2313-B-002-239). 


\section{APPENDIX}

In this study the parameters are determined by differentiating the following equation

$$
H=\sum_{m=1}^{n}\left[u_{1, m}^{2}\left(\sum_{p=1}^{h}\left(w_{p}\left({ }_{p} r_{i}^{m}-{ }_{p} g_{i}\right)\right)^{2}\right)+\left(1-u_{1, m}\right)^{2}\left(\sum_{p=1}^{h}\left(w_{p}\left({ }_{p} r_{i}^{m}-{ }_{p} b_{i}\right)\right)^{2}\right)\right]
$$

Differentiating Equation (A1) yields

$$
\begin{aligned}
\frac{\mathrm{d} H}{\mathrm{~d} u_{1, m}} & =2 u_{1, m}\left(\sum_{p=1}^{h}\left(w_{p}\left({ }_{p} r_{i}^{m}-{ }_{p} g_{i}\right)\right)^{2}+\sum_{p=1}^{h}\left(w_{p}\left({ }_{p} r_{i}^{m}-{ }_{p} b_{i}\right)\right)^{2}\right)-2 \sum_{p=1}^{h}\left(w_{p}\left({ }_{p} r_{i}^{m}-{ }_{p} b_{i}\right)\right)^{2} \\
\frac{\mathrm{d}^{2} H}{\mathrm{~d} u_{1, m}^{2}} & =2\left(\sum_{p=1}^{h}\left(w_{p}\left({ }_{p} r_{i}^{m}-{ }_{p} g_{i}\right)\right)^{2}+\sum_{p=1}^{h}\left(w_{p}\left({ }_{p} r_{i}^{m}-{ }_{p} b_{i}\right)\right)^{2}\right)^{2}
\end{aligned}
$$

Equation (A3) is a convex function. The minimum point is always found when $\frac{\mathrm{d} H}{\mathrm{~d} u_{1, m}}=0$. Thus we obtain

$$
u_{1, m}=\frac{1}{1+\frac{\sum_{p=1}^{h}\left(W_{p}\left({ }_{p} r_{i}^{m}-{ }_{p} g_{i}\right)^{2}\right.}{\sum_{p=1}^{h}\left(W_{p}\left({ }_{p} r_{i}^{m}-{ }_{p} b_{i}\right)\right)^{2}}}
$$

\section{REFERENCES}

Archibald TW, McKinnon KIM, Thomas LC. 1996. An aggregate stochastic dynamic programming model of multireservoir systems. Water Resources Research 33(2): 333-340.

Bellman R. 1957. Dynamic Programming. Princeton University Presses: Princeton, NJ.

Bras RL, Buchanan RB, Curry KC. 1983. Real time adaptive closed loop control of reservoirs with the High Aswan Dam as a case study. Water Resources Research 19(1): 33-52.

Chen S, Jiang Y. 1990. Principle of multi-objective hierarchial evaluation method of water resources plans. Journal of Dalian University of Technology 31(1): 95-100. (In Chinese.)

Datta B, Houck MH. 1984. A stochastic optimization model for real-time operation of reservoirs using uncertain forecasts. Water Research 20(8): 1039-1064.

Deng J. 1984. The Theory and Methods of Socio-economic Grey Systems. Science Press: Beijing. (In Chinese.)

Hall WA, Buras N. 1961. The dynamic programming approach to water resources development. Journal of Geophysical Research 66(2): 517-520.

Hsu SK. 1995. Shortage indices for water-resources planning in Taiwan. Journal of Water Resources Planning and Management 121(2): 119-131.

Karamouz M, Vasiliadis HV. 1992. Bayesian stochastic optimization of reservoir operation using uncertain forecasts. Water Resources Research 28(5): 1221-1232.

Kelman J, Stedinger JR, Cooper LA, Yuan S-Q. 1990. Sampling stochastic dynamic programming applied to reservoir operation. Water Resources Research 26(3): 447-454.

Stedinger JR, Sule BF, Loucks DP. 1984. Stochastic dynamic programming models for reservoir operation optimization. Water Resources Research 20(11): 1499-1505.

Trezos T, Yeh WW-G. 1987. Use of stochastic dynamic programming for reservoir management. Water Resources Research 23(6): $983-996$. Zadeh LA. 1965. Fuzzy sets. Information and Control 8: 338-353. 